\title{
Smart, Remote, and Targeted Health Care Facilitation Through Connected Health: Qualitative Study
}

Sonia Chien-I Chen ${ }^{1 *}$, BA, MSc, PhD; Ridong $\mathrm{Hu}^{{ }^{*}}$, PhD; Rodney McAdam ${ }^{2 *}, \mathrm{PhD}$

\footnotetext{
${ }^{1}$ Institute of Quantitative Economics, Huaqiao University, Xiamen, China

${ }^{2}$ Ulster Business School, Ulster University, Newtownabbey, United Kingdom

*all authors contributed equally
}

\section{Corresponding Author:}

Ridong $\mathrm{Hu}, \mathrm{PhD}$

Institute of Quantitative Economics

Huaqiao University

No. 668, Jimei Avenue

Jimei dist

Xiamen, 361021

China

Phone: 8617750619886

Email: j_rdhu@hqu.edu.cn

\begin{abstract}
Background: Societies around the world are aging. Widespread aging creates problems for social services and health care practices. In this light, research on connected health $(\mathrm{CH})$ is becoming essential. $\mathrm{CH}$ refers to a variety of technological measures that allow health care to be provided remotely with the aim of increasing efficiency, cost-effectiveness, and satisfaction on the part of health care recipients. $\mathrm{CH}$ is reshaping health care's direction to be more proactive, more preventive, and more precisely targeted and, thus, more effective. $\mathrm{CH}$ has been demonstrated to have great value in managing and preventing chronic diseases, which create huge burdens on health care and social services. In short, $\mathrm{CH}$ provides promising solutions to diseases and social challenges associated with aging populations. However, there are many barriers that need to be overcome before $\mathrm{CH}$ can be successfully and widely implemented.
\end{abstract}

Objective: The research question of this study is as follows: How can $\mathrm{CH}$ facilitate smart, remote, and targeted health care? The objective is to identify how health care can be managed in more comprehensive ways, such as by providing timely, flexible, accessible, and personalized services to preserve continuity and offer high-quality seamless health care.

Methods: A qualitative approach was used based on 60 multistage, semistructured stakeholder interviews.

Results: The results can be divided into two functions of $\mathrm{CH}$ : ecosystem and platform. On the one hand, the interviews enabled the authors to develop a stakeholder classification and interaction diagram. These stakeholders interacted sequentially to provide technology-based content to end users. On the other hand, interviewees reflected on how $\mathrm{CH}$ serves as a platform to address remote monitoring and patient self-management. In the Discussion section, three innovation strategies are discussed to reflect the manner in which $\mathrm{CH}$ promotes smart, timely, and precise health care.

Conclusions: This study indicates that it is essential to continually revise $\mathrm{CH}$ business models, given the ongoing and rapid changes in technology across groups of $\mathrm{CH}$ stakeholders. We also found that global trends toward smart, timely, and precise health care shape what individuals expect from products and services, providing firms with unique opportunities for growth.

(J Med Internet Res 2020;22(4):e14201) doi: 10.2196/14201

\section{KEYWORDS}

connected health care; smart health care; health care quality; access; remote monitoring; precision medicine; self-management 


\section{Introduction}

\section{Background}

Our society is aging. This trend is projected to result in increased chronic health conditions and potential labor shortages. As traditional health care models are not fully equipped to face the unique challenges of providing health care for an aging society, innovative practices are being proposed and developed to decrease the pressures of widespread aging. Through self-management and remote monitoring platforms, connected health $(\mathrm{CH})$ has been offered as a new technology-based model of health care delivery that presents a promising solution for future, aging-oriented health care [1].

The rise of $\mathrm{CH}$ is attributable to four factors. The first factor is related to the widespread tendency to pursue excellence in health care through the promotion and monitoring of health care services' quality, efficiency, safety, and level of customer service. Because of this tendency, health professionals and institutions demand that health care services be more accessible, of a higher quality, and more efficient, so they often turn to $\mathrm{CH}$ [2]. Second, aging populations have increased health care costs due to the increase in chronic conditions, higher survival rates among patients fighting serious diseases, and longer lifespans that accompany aging [3]. Thus, the health care economy has become more complex than in the past as evidenced by the rising costs of caring for changing demographics. Third, increasingly frequent provider shortages and other relevant issues, including the geographic dispersion of families and troubling disparities in care between ethnic groups, are significant concerns for aging populations [4]. Lastly, patients in varying contexts have demanded better customer service from health care providers [5]. Some authors suggest that the development of consumerism in health care may be a catalyst for the development of patient-centric health care [6-8]. In combination, these factors have created a stronger impetus to force health care innovation from both within and outside the ecosystem.

Although $\mathrm{CH}$ seeks to make health care services more proactive, preventive, and precisely targeted, there are many challenges and barriers to its sustainable implementation that need to be addressed and overcome. These challenges include the cost of devices, privacy and data security concerns, health system bureaucracy, and training health professionals and patients to use new technologies. This study identifies strategies to make health care systems smarter, timelier, and more precise by exploring the interaction of stakeholders in the $\mathrm{CH}$ ecosystem and $\mathrm{CH}$ 's role as a platform.

\section{Study Design and Conceptual Framework}

Figure 1 illustrates the conceptual framework that forms the basis for this study. First, we reviewed definitions of $\mathrm{CH}$ in the literature to determine its main features. Second, three features of timely, smart, and targeted care were determined and applied to evaluate how patient-centric health care services can be delivered through $\mathrm{CH}$. Third, we conducted interviews and engaged case studies to identify effective strategies for the implementation of $\mathrm{CH}$. Although $\mathrm{CH}$ is promising, many challenges, such as issues of cost, infrastructure, technology, and business sustainability, still remain to be overcome. Therefore, we examined extant and innovative strategies for implementing $\mathrm{CH}$ and/or augmenting existing health care systems and interviewed relevant stakeholders in the $\mathrm{CH}$ ecosystem to discover how to reach these goals. Finally, the results were analyzed with an eye to expressing the implications of addressing a comprehensive health care system that can fulfill patients' needs and suggestions on how to do so.

Figure 1. The study's design and conceptual framework.

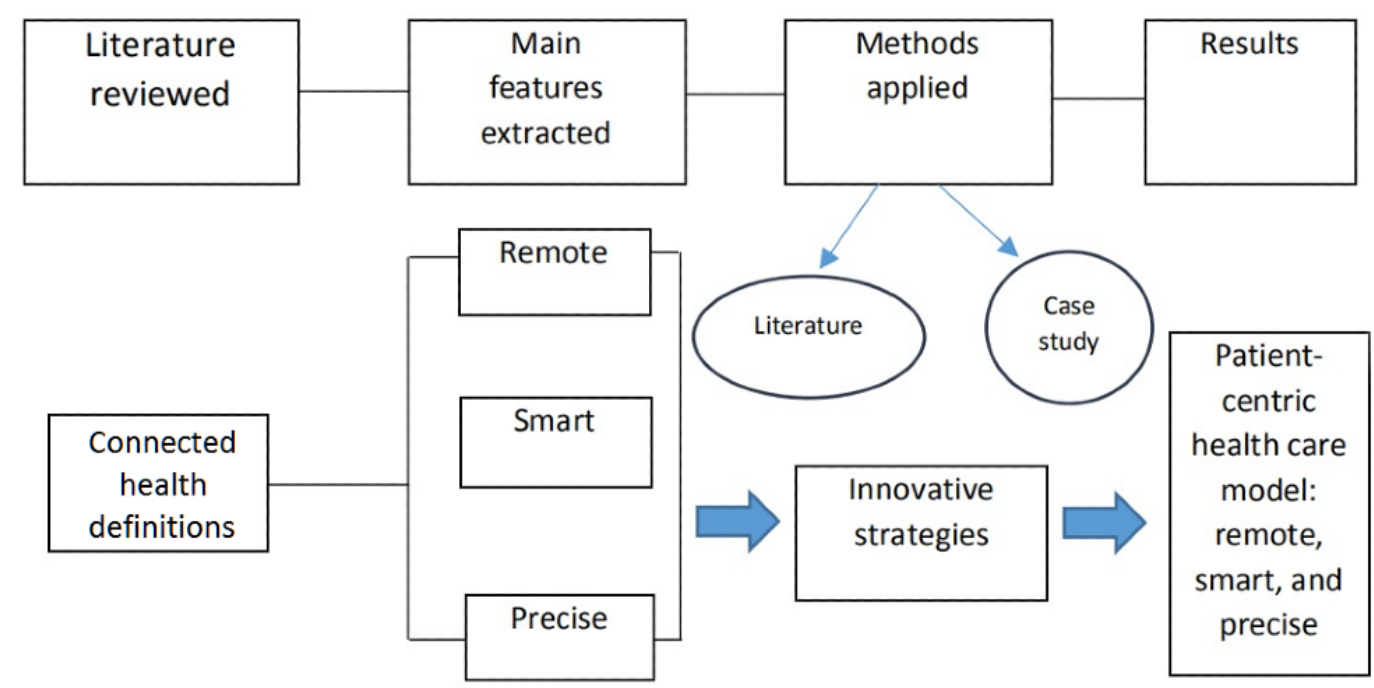

\section{Definition of Connected Health}

Broadly speaking, $\mathrm{CH}$ is an umbrella term that covers the telemedicine family spectrum. An increasingly developed base of knowledge around $\mathrm{CH}$ and $\mathrm{CH}$ practices has generated many definitions of exactly what $\mathrm{CH}$ is $[2,8]$. For instance, the

American Medical Association (AMA) defines $\mathrm{CH}$ as a model that utilizes technology to maximize health care resources and offer enhanced, flexible opportunities for patients to engage with clinicians and better self-manage their care [9]. In order to achieve these goals, many technologies, including telemedicine and mobile health, are used to facilitate remote, 
mobile, and site-to-site medical care. To focus our research, we classified definitions of $\mathrm{CH}$ into three types based on their salient features: remote, smart, and precise. This study then defines $\mathrm{CH}$ as a platform that offers remote monitoring and self-management, helping patients to address their own health care needs in a smart, timely, and precise manner through information and communication technologies (ICTs). Below, we briefly discuss our three classifications of $\mathrm{CH}$ definitions.

\section{Remote Health Care}

Remote medical care is a key feature of $\mathrm{CH}$ [3-5,9-12]. Studies indicate that both the concept of remote health care and the practical application of information technology systems to health care include aspects of remote medical care, such as a telecare medicine information system, a personally controlled health records system, and patient monitoring. These studies further point out that in $\mathrm{CH}$ applications, "user authentication can ensure the legality of patients" care" [13]. Remote health care-focused definitions of $\mathrm{CH}$ are often seen as part of a new lexicon for telemedicine, even though these definitions and their proponents may exhibit a greater focus on how to best connect clients and health care professionals.

\section{Smart Health Care}

Although technology plays a significant role in $\mathrm{CH}$, researchers indicate that $\mathrm{CH}$ is not just about technologies, but its relationship with people and the health care system [14]. Smart-oriented definitions of $\mathrm{CH}$ demonstrate how $\mathrm{CH}$ is not just about health care and technology, but about managing patients and their care [12,14]; they indicate that $\mathrm{CH}$ is a new model for health management and that $\mathrm{CH}$ has the potential to put the correct information in the correct hands at the correct time, thus improving decision making and care. These decisions can "save lives, save money and ensure a better quality of life during and after treatment." $\mathrm{CH}$ can help deliver better health outcomes by allocating health resources more efficiently and effectively via the better management and integration of health care systems and services, which are, in theory, typified by smart health care.

According to the literature review, $\mathrm{CH}$ tends to be a combination of people, processes, and technology [4,15]. Take, for example, the following definition: "connected health....refers to a conceptual model for health management where devices, services or interventions are designed around the patient's needs" [15]. Based on this definition, $\mathrm{CH}$ is a patient-centered care model where the patient is at the center of the processes that connect stakeholders-a process that takes place over a variety of settings, from the patient's home to an acute care setting. This definition also indicates that patient care pathways, revenue models, and data analytics can be connected through technology in the $\mathrm{CH}$ platform. Therefore, technology can enable the implementation of a more proactive, episodic health care model, which is starkly different from the more reactive model of conventional health care. With the assistance of technology, health care professionals, patients, and/or caregivers can be empowered to engage in more effective and efficient health care.

\section{Precise Health Care}

$\mathrm{CH}$ differs from conventional health care in that it collects data in a timely and seamless fashion, thus providing more information for clinicians to address patients' precise health care needs [2]. Furthermore, "stakeholders in the process are connected...using timely sharing and presentation of accurate and pertinent information regarding patient status through the smarter use of data, devices, communication platforms and people" [16]. Therefore, through $\mathrm{CH}$, patients can receive care in a manner that is as efficient and precise as possible.

\section{Value Propositions Based on Trends}

As noted above, the patient-centric values of $\mathrm{CH}$ can be defined and classified into smart, timely, and precise care. The relevant literature reviews how such values can be proposed and captured through strategies. Values are created by a value chain comprising suppliers, firms, and buyers [17]. How much value can be captured via strategies depends on the capacity of these strategies to add value to a given service or care practice. The analysis of value - based business strategies depends on the cooperative game theory among firms, how they act toward one another as competitors, firms' willingness to pay, and the opportunity costs of acting. Although value types vary, value propositions in business models are the key to increase the attraction of firms' willingness to pay [18]. Three innovative strategies have been identified to potentially rebuild the business model: infuse and augment, combine and transcend, and counteract and reaffirm [19]. We review examples from prominent companies in the literature to support the idea that these strategies can influence success in service innovation $[12,19]$. Furthermore, innovation should be inspired by clients' motivations and innovations' appeal to clients; therefore, using these strategies may be an effective way to achieve this goal [20].

Despite the importance of value propositions and strategic planning, most research focuses on two primary performance factors: cost-effectiveness and operational efficiency [21]. Although the qualities of timely, smart, and precise health care are essential to create a patient-centric health care model, more research is required to explore how these goals can be achieved in practice. According to the literature, technology is not the sole factor driving more personalized health care services. Management and other factors that involve qualitative components may help to maintain human esteem and dignity through a CH platform [22,23]. Although CH's value has been demonstrated in the management of chronic diseases, researchers expect tremendous progress in $\mathrm{CH}$ 's applications in disease prevention [24]. The proliferation of advanced technology enables $\mathrm{CH}$ to be more proactive than conventional medicine [25]. Thus, a qualitative approach is employed to achieve the goal of providing more proactive, preventative, and precise health care.

Despite the positive impacts of $\mathrm{CH}$ described above, barriers to implementing $\mathrm{CH}$ still need to be identified and overcome in order to accelerate and deliver more effective and cost-efficient health care models [15]. Health care that is proactive, preventive, and targeted is likely to reduce many of the burdens of an aging society [26,27]. Yet, there is still a gap 
in the research regarding how medical interventions such as the implementation of $\mathrm{CH}$ can both be effective and also maintain the dignity of elderly patients [28]. To fill this gap, this study explores the relationship between technology and wellness, and how both have been optimized in certain cases. It identifies the preconditions and essential requirements for developing a $\mathrm{CH}$ ecosystem and provides typical, illustrative case studies to answer the research question. Therefore, this study aims to qualitatively explore and discover hitherto unknown aspects of how health care can be more comprehensive by being smarter, timelier, and more precise.

\section{Methods}

\section{Overview}

This study uses literature reviews and empirical research to investigate how timely, smart, and targeted health care can be achieved via $\mathrm{CH}$ platforms. Although the majority of $\mathrm{CH}$ research has used quantitative methods to test and validate assumptions [29-31], this study utilized a qualitative research method, conducting 60 interviews that were designed to answer the research question and explore the unknown and novel phenomena of health care in an aging society. We employed three methods to identify stakeholders in the $\mathrm{CH}$ ecosystem: (1) reviewing the $\mathrm{CH}$ organizational process assets (ie, the plans, processes, policies, procedures, and knowledge bases specific to and used by the performing organization) and their environmental factors; (2) interviewing experts in the field of $\mathrm{CH}$; and (3) conducting brainstorming sessions. Regarding $\mathrm{CH}$-related value propositions, the strategies based on trends in the literature are relevant. Therefore, the innovative strategies proposed in previous studies [19] are employed as a foundation for classifying and discussing the results of this study.

\section{Research Methodology}

Owing to the developmental nature of $\mathrm{CH}$ literature, this study used an exploratory and inductive theory-building approach based on our 60 multistage, semistructured stakeholder interviews. The target sample we used to address the study aims and research question was $\mathrm{CH}$ stakeholders and experts, including medical researchers, industry leaders, government officials, and end users. This qualitative methodology facilitates a better understanding of a rapidly developing discourse, such as that of $\mathrm{CH}$, by exploring and using insightful input, having broader discussions, and synthesizing diverse opinions [29,31]. Thus, this approach can be used to bridge the knowledge gaps in literature.

\section{Recruitment Criteria of the Participants}

Stakeholders and experts were selected for the interviews according to the literature review and snowball sampling [32]. These participants were interviewed on a voluntary basis and gave verbal consent according to ethical guidelines. This study was approved by Ulster University's institutional review board (reference No. RG3 RMcAdam2). The study's participants included health care professionals, industry players, academic researchers, and government agents. The researchers identified participants' backgrounds, competencies, gender, etc, as they may relate to the outcomes of this research. Our semistructured interview guide comprised the following: (1) working sectors, (2) background information, (3) gender, and (4) levels of competency.

Taiwan was selected as a case study to explore the myriad phenomena accompanying aging populations and test strategies for the development and implementation of $\mathrm{CH}$. We chose this case study because Taiwan has experienced both significant challenges and progress in its core health care activities. Another reason for choosing Taiwan was because of its complete $\mathrm{CH}$ business ecosystem, which includes mature ICT applied to health care practices and an integrated health care system. Approaching our research questions through the multi-stakeholder case study of Taiwan helps us to explore rich contextual information by asking what and how questions, rather than generalizing principles to a population [29,31]. Multistage interviews were conducted to deepen the research by iteratively collecting data [29]. The data were collected using a multistage approach with interviewees, considering the $\mathrm{CH}$ ecosystem's progressive and multidimensional nature. This is illustrated in Tables 1-3.

Pilot interviews were conducted $(\mathrm{n}=16)$ with key $\mathrm{CH}$ influencers across stakeholder groupings to explore the $\mathrm{CH}$ phenomenon and identify the primary contributing factors and stakeholders in Taiwan's CH ecosystem. Next, Stage 1 interviews $(n=22)$ were held with $\mathrm{CH}$ stakeholders who were identified from the pilot stage interviews' findings and analysis. An analysis was conducted using a snowball sampling method [32]. Stage 2 interviews $(n=22)$ were conducted 1 year after the Stage 1 interviews to explore how systemic problems develop and persist over time in $\mathrm{CH}$ ecosystems and to review longitudinal changes from a Business Model Innovation (BMI) perspective in terms of the sustainability of $\mathrm{CH}$.

The pilot interviews were conducted in order to confirm the need for, and significance of, further $\mathrm{CH}$ research. This pilot study was also advantageous because it identified potential directions and perspectives for conducting the multistage interviews, which helped us collect data more effectively. The results of the pilot interviews suggested that further study of $\mathrm{CH}$ is meaningful. Barriers that obscured the development of $\mathrm{CH}$ were further investigated in the Stage 1 interviews. As mentioned above, 16 interviewees were included in the pilot interviews (see Table 1). The majority were health care providers, as they have rich experience of $\mathrm{CH}$ technologies and services. Their feedback was significant in reflecting the effectiveness of $\mathrm{CH}$ products and services. Therefore, understanding their views is important in the design of successful and user-friendly interactive systems. This pilot interview focused on medical doctors and health professionals rather than patients and their families, due to ethical concerns. 
Table 1. Profiles of the pilot study interviewees.

\begin{tabular}{|c|c|c|c|c|}
\hline Participant number & Sector and participants in that sector $(\mathrm{n}=16), \mathrm{n}(\%)$ & Organization & Gender $^{\mathrm{a}}$ & Title \\
\hline 1 & Industry, 2 (13) & June Sun Digicom & Male & General Manager \\
\hline 2 & Industry, 2 (13) & DigiO2 & Male & Tech Advisor \\
\hline 3 & Government or semigovernment, 2 (13) & Taiwan Forces for Medical Travel & Male & $\begin{array}{l}\text { Chief Executive Officer } \\
\text { (CEO) }\end{array}$ \\
\hline 4 & Government or semigovernment, 2 (13) & Taiwan Forces for Medical Travel & Female & Vice Project Manager \\
\hline 5 & Academia, 1 (6) & $\begin{array}{l}\text { Taipei Medical University, School of } \\
\text { Gerontology Health Management, } \\
\text { College of Nursing }\end{array}$ & Female & $\begin{array}{l}\text { Assistant Professor or } \\
\text { Attending Physician }\end{array}$ \\
\hline 6 & Health care providers, 11 (69) & Chang Gung Memorial Health Village & Female & Staff \\
\hline 7 & Health care providers, 11 (69) & Antai Medical Care Hospital & Male & $\begin{array}{l}\text { Director or General } \\
\text { Practitioner (GP) }\end{array}$ \\
\hline 8 & Health care providers, 11 (69) & Antai Medical Care Hospital & Female & GP \\
\hline 9 & Health care providers, $11(69)$ & San-Chung Health Center & Female & Head Nurse \\
\hline 10 & Health care providers, 11 (69) & YR Chinese Medicine Clinic & Male & Doctor \\
\hline 11 & Health care providers, 11 (69) & YR Chinese Medicine Clinic & Female & Manager \\
\hline 12 & Health care providers, 11 (69) & Tri-service General Hospital & Male & Medical Doctor \\
\hline 13 & Health care providers, 11 (69) & Taiwan University Hospital & Male & Medical Doctor \\
\hline 14 & Health care providers, 11 (69) & $\begin{array}{l}\text { Kaohsiung Municipal Hsiaokang } \\
\text { Hospital }\end{array}$ & Female & Pharmacist \\
\hline 15 & Health care providers, 11 (69) & $\begin{array}{l}\text { Zhang Bi Zheng Family Physicians' } \\
\text { Clinic }\end{array}$ & Male & Director or GP \\
\hline 16 & Health care providers, 11 (69) & Home Physician & Male & Therapist \\
\hline
\end{tabular}

${ }^{\mathrm{a}}$ The sample was made up of 56\% (9/16) males and 44\% (7/16) females. 
Table 2. Profiles of Stage 1 interviewees.

\begin{tabular}{|c|c|c|c|c|}
\hline Participant number & Sector and participants in that sector $(\mathrm{n}=22), \mathrm{n}(\%)$ & Organization & Gender $^{\mathrm{a}}$ & Title \\
\hline 17 & Industry, 8 (36) & Netown & Male & Sales \\
\hline 18 & Industry, 8 (36) & Far EasTone Telecommunications & Male & Senior Engineer \\
\hline 19 & Industry, 8 (36) & Far EasTone Telecommunications & Male & Senior Engineer \\
\hline 20 & Industry, 8 (36) & Huede Technology & Male & $\begin{array}{l}\text { Chief Executive Officer } \\
\text { (CEO) }\end{array}$ \\
\hline 21 & Industry, 8 (36) & Huede Technology & Female & $\begin{array}{l}\text { Nurse or Health Man- } \\
\text { agement }\end{array}$ \\
\hline 22 & Industry, 8 (36) & Guidercare & Male & Vice President \\
\hline 23 & Industry, 8 (36) & Acomotech & Male & Tech Advisor \\
\hline 24 & Industry, 8 (36) & Medsense & Male & Founder \\
\hline 25 & Government, 2 (9) & Ministry of Health \& Welfare & Male & $\begin{array}{l}\text { Director of } \mathrm{ICT}^{\mathrm{b}} \text { Depart- } \\
\text { ment }\end{array}$ \\
\hline 26 & Government, 2 (9) & Sang Chung Health Center & Male & Administrator \\
\hline 27 & Academia, 3 (14) & National Taiwan University & Male & Director or Professor \\
\hline 28 & Academia, 3 (14) & $\begin{array}{l}\text { National Taipei University of Tech- } \\
\text { nology }\end{array}$ & Female & Lecturer \\
\hline 29 & Academia, 3 (14) & $\begin{array}{l}\text { UL (Underwriters Laboratories) Life } \\
\& \text { Health }\end{array}$ & Male & Sales Manager \\
\hline 30 & Health care providers, $9(41)$ & Luo Dong Care Institute & Male & $\mathrm{CEO}$ \\
\hline 31 & Health care providers, $9(41)$ & En Chu Kong Hospital & Female & Senior Nurse \\
\hline 32 & Health care providers, $9(41)$ & $\begin{array}{l}\text { Taoyuan Fu Hsing Township Health } \\
\text { Station }\end{array}$ & Male & $\begin{array}{l}\text { Director or General } \\
\text { Practitioner (GP) }\end{array}$ \\
\hline 33 & Health care providers, $9(41)$ & $\begin{array}{l}\text { Taoyuan Fu Hsing Township Health } \\
\text { Station }\end{array}$ & Female & Head Nurse \\
\hline 34 & Health care providers, $9(41)$ & $\begin{array}{l}\text { Taipei Medical University, Telehealth } \\
\& \text { Telecare Center }\end{array}$ & Female & $\begin{array}{l}\text { Director or Health } \\
\text { Management }\end{array}$ \\
\hline 35 & Health care providers, $9(41)$ & Mennonite Christian Hospital & Male & $\begin{array}{l}\text { Management of Infor- } \\
\text { mation Service } \\
\text { (MIS) Director }\end{array}$ \\
\hline 36 & Health care providers, 9 (41) & Mennonite Christian Hospital & Female & Head Nurse \\
\hline 37 & Health care providers, $9(41)$ & $\begin{array}{l}\text { Taiwan University Hospital, Tele- } \\
\text { health Center }\end{array}$ & Female & $\begin{array}{l}\text { Nurse or Health Man- } \\
\text { agement }\end{array}$ \\
\hline 38 & Health care providers, $9(41)$ & Taiwan University Hospital & Male & GP \\
\hline
\end{tabular}

${ }^{\mathrm{a}}$ The sample was made up of $68 \%$ (15/22) males and $32 \%$ (7/22) females.

${ }^{\mathrm{b}} \mathrm{ICT}$ : information and communication technology. 
Table 3. Profiles of Stage 2 interviewees.

\begin{tabular}{|c|c|c|c|c|}
\hline Participant number & Sector and participants in that sector $(n=22), n(\%)$ & Organization & Gender $^{\mathrm{a}}$ & Title \\
\hline 39 & Industry, 15 (68) & $\begin{array}{l}\text { Agfa HealthCare Image (imaging } \\
\text { technology) }\end{array}$ & Male & Consultant \\
\hline 40 & Industry, 15 (68) & $\begin{array}{l}\text { Asus Compute Inc (internet technolo- } \\
\text { gy) }\end{array}$ & Male & Senior Manager \\
\hline 41 & Industry, 15 (68) & $\begin{array}{l}\text { G-cloud UK (cloud computing tech- } \\
\text { nology) }\end{array}$ & Male & $\begin{array}{l}\text { Chief Executive Officer } \\
\text { (CEO) }\end{array}$ \\
\hline 42 & Industry, 15 (68) & $\begin{array}{l}\text { Sheng-En Development Co (value } \\
\text { network) }\end{array}$ & Male & Division Manager \\
\hline 43 & Industry, 15 (68) & $\begin{array}{l}\text { Asus Cloud Corporation (internet, } \\
\text { storage, and cloud computing technol- } \\
\text { ogy) }\end{array}$ & Male & Department Director \\
\hline 44 & Industry, 15 (68) & Far EasTone Telecommunications & Male & Director \\
\hline 45 & Industry, 15 (68) & Taidoc/Fora Care & Male & Sales Manager \\
\hline 46 & Industry, 15 (68) & Smart Catch International Co, Ltd & Female & Specialist \\
\hline 47 & Industry, 15 (68) & MitraStar & Male & Senior Director \\
\hline 48 & Industry, 15 (68) & Gemtek Technology Co, Ltd & Female & Product Manager \\
\hline 49 & Industry, 15 (68) & Z-Com/ZWA Inc & Male & Sales Director \\
\hline 50 & Industry, 15 (68) & $\begin{array}{l}\text { Isentek/Partnership with TXCorpra- } \\
\text { tion }\end{array}$ & Female & Deputy Sales Manager \\
\hline 51 & Industry, 15 (68) & $\begin{array}{l}\text { Through Tek Technology (TUTK) } \\
\text { Co, Ltd }\end{array}$ & Female & Product Manager \\
\hline 52 & Industry, 15 (68) & Pioneer Material Precision Tech & Female & Buyer \\
\hline 53 & Industry, 15 (68) & Auden Group & Female & Executive Assistant \\
\hline 54 & Health care providers, $6(27)$ & $\mathrm{CH}^{\mathrm{b}}$ Healthy Village (value network) & Female & Division Manager \\
\hline 55 & Health care providers, $6(27)$ & $\begin{array}{l}\text { Changhua Christian Hospital }(\mathrm{CCH}) \\
\text { (telecare health service center) } \\
\left(\mathrm{BMI}^{\mathrm{c}}\right)\end{array}$ & Female & Head Nurse \\
\hline 56 & Health care providers, $6(27)$ & $\begin{array}{l}\text { CK Memorial Hospital (health profes- } \\
\text { sional) }\end{array}$ & Female & Senior Pharmacist \\
\hline 57 & Health care providers, $6(27)$ & $\begin{array}{l}\text { Tai Tong Health Center ( } \mathrm{CH} \text { con- } \\
\text { sumer in remote area) }\end{array}$ & Male & Medical Doctor \\
\hline 58 & Health care providers, $6(27)$ & Show-Chwan Hospital & Female & Nurse \\
\hline 59 & Health care providers, $6(27)$ & Show-Chwan Hospital & Female & Nurse \\
\hline 60 & Academia, 1 (5) & $\begin{array}{l}\text { Industrial Technology Research Insti- } \\
\text { tute/Ministry of Economic Affairs } \\
\text { (MOEA) }\end{array}$ & Female & Manager \\
\hline
\end{tabular}

\footnotetext{
${ }^{\mathrm{a}}$ The sample was made up of $45 \%$ (10/22) males and 55\% (12/22) females.

${ }^{\mathrm{b}} \mathrm{CH}$ : connected health.

${ }^{\mathrm{c}}$ BMI: Business Model Innovation.
}

The Stage 1 interview asked participants to consider problems reported in the literature on $\mathrm{CH}$. These questions covered the cost of implementing $\mathrm{CH}$ and creating the necessary infrastructure and technology, business sustainability, different $\mathrm{CH}$ business models, collaboration, and communication-related issues. The results were analyzed to identify further knowledge gaps and to increase the depth of current knowledge. Stage 2 interviews addressed the gaps identified in Stage 1 and sought to discover insights of sustaining $\mathrm{CH}$ businesses. Due to the challenges of time limits and the distance of remote areas in
Taiwan during data collection, we required two phases of interviews to ensure that we adequately covered some important issues and themes.

Interviews lasted between 1 and 2 hours and were transcribed and coded using NVivo 10 (QSR International) qualitative data analysis software. Different data sources, including interviews, documents, and public records, were synthesized and coded for data triangulation to increase the credibility and validity of the study's results [29]. Data were cleaned through an integration 
process to merge different terms with similar meanings. For example, $\mathrm{CH}$ could be called remote health, telehealth, and telecare in the interviews; these terms were merged because the interviewees used them to refer to the same thing. Inaccurate, incomplete, or irrelevant parts of the dataset were detected, corrected, or removed from the raw data in the data-cleaning phase. The data were then clustered and coded.

The data analysis strategy of this study included thematic and systematic approaches in a collaborative qualitative analysis. The data collected underwent a deep familiarization, and this led to the development of major themes, which in turn organized the thematic analysis. This study utilized NVivo 10 to analyze the interview data by grouping words or sentences based on how frequently they occurred in the interviews. Content analysis was conducted to objectively and systematically induce meaning on the content through coding [33]. This analysis adopted a grounded theoretical approach. Initially, we drew out coded data and themes with the potential for rapid change. The number of new and emerging themes gradually diminished, and the number of refinements to these themes decreased until theoretical saturation was met. The data collection and iterative analysis were repeated until saturation occurred. The data were summarized, confirmed, and discussed in subsequent interviews with the same interviewees from the pilot stage, Stage 1, and Stage 2 . This process was intended to ensure the data's reliability and validity. This method is beneficial as the interviews' primary content can be confirmed and corrected quickly by experts in

Figure 2. Results of thematic analysis. the $\mathrm{CH}$ ecosystem. Throughout the process, constant reference to existing literature contributed to the data analysis [29].

\section{Results}

This study employed both thematic analysis and systematic content analysis. The results are sequentially demonstrated in the following subsections.

\section{Results of Thematic Analysis}

Figure 2 shows the results of thematic analysis in terms of how qualitative data were coded and iteratively compared and integrated into themes. For instance, the description "the distance and time spent for remote residents visiting health facilities..." and the non-cost-effectiveness of "...remote health..." were coded as geographic isolation barriers and developed into the theme of remote health according to iterative comparison. Other interview data were clustered and merged according to a similar mechanism.

Figure 3 illustrates a map of how codes converged as themes from the qualitative data. Codes for integration, communication, bureaucracy, ecosystem, self-management, and interdisciplinary talent were merged as the theme smart health. Seamless, contiguity, prevention, targeted health, and personalized health were categorized into precision medicine. The theme remote health covered flexibility, accessibility, empowerment, timely manner, geographic isolation, wider coverage, and security concerns. In summary, smart health, precision medicine, and remote health consisted of the $\mathrm{CH}$ features.

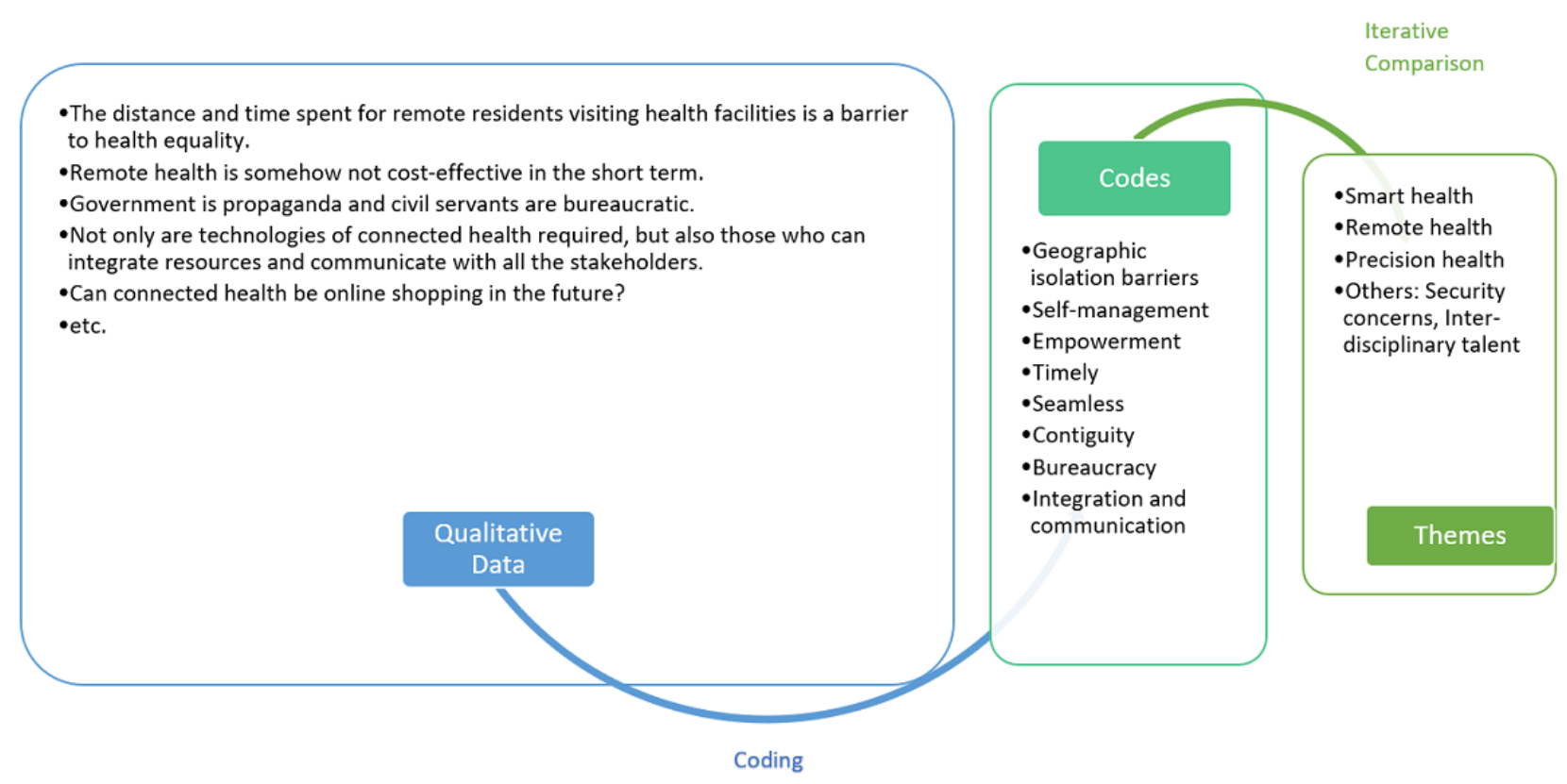


Figure 3. Thematic analysis mapping.

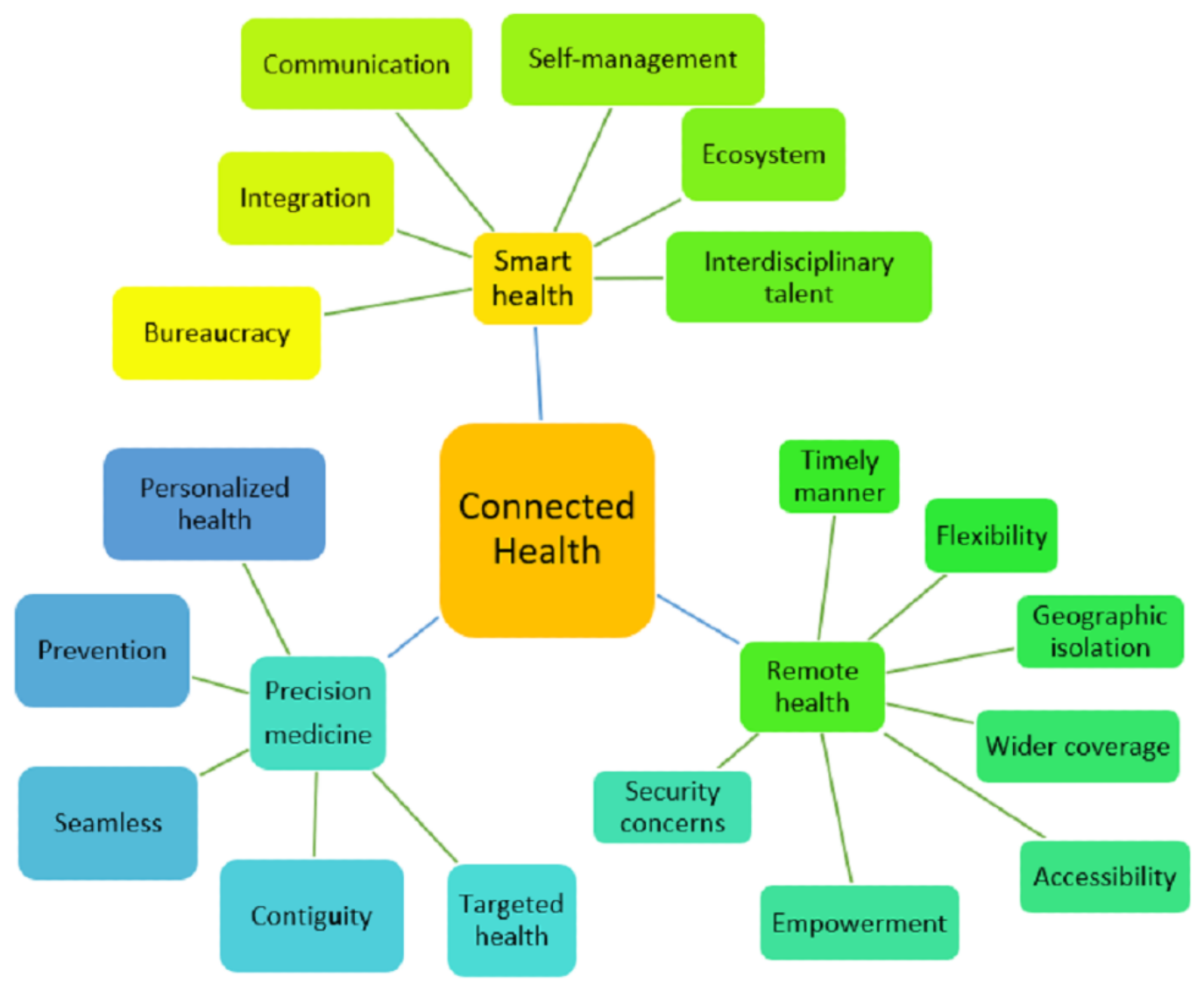

\section{Results of Systematic Analysis}

NVivo 10 was used to analyze the interview data by grouping words or sentences based on how frequently they occurred in the interviews. The results are shown in Table 4 and Multimedia Appendix 1. According to the word cloud of Multimedia Appendix 1 it is noticeable that keywords such as care, business, data, system, model, time, technology, government, and management were most frequently mentioned in the interviews. The word-frequency framework was used to identify meaningful words and their potential significance. The words that frequently occurred were clustered into three themes: technology, organization, and leadership and management issues (see Table 4). These words that were shown the most frequently were compared according to the original context and grouped into key themes.

Results of the analyses conducted on the interview data are summarized and presented in the following sections: (1) $\mathrm{CH}$ as an ecosystem, (2) $\mathrm{CH}$ as a platform, and (3) CH's innovative strategies based on value propositions. First, the principles adopted to identify stakeholders in the ecosystem, based on the power and interest of their ability to affect CH's objectives, were reviewed. The stakeholder interaction diagram (see Figure 4) was created based on the foundation of a previous study that identified stakeholders in the $\mathrm{CH}$ ecosystem [34]. In our diagram, governments take the lead and initiate the infrastructure projects needed to implement $\mathrm{CH}$, and the sequential interaction that follows provides technology-based content to end-user stakeholders. Second, $\mathrm{CH}$ as a platform enables remote monitoring and makes patients' self-management possible.

Moreover, interviewees contributed insights regarding the challenges that the implementation of $\mathrm{CH}$ faces and how they can be addressed. Third, CH's innovative strategies based on value propositions were referred to the value propositions from current trends, which may inspire practitioners and policy makers. Three innovation strategies, based on information emanating from Harvard Business School, are discussed to reflect how timely, smart, and targeted health care can be delivered via the $\mathrm{CH}$ platform [12].

Figure 4 illustrates the overall $\mathrm{CH}$ ecosystem, along with relationships between stakeholders and players [35]. Figure 4 identifies eight types of stakeholders and players, which can be classified into three sectors: government, industry, and academia. Policy making and infrastructure building, led by government, initiates the implementation of $\mathrm{CH}$. Figure 4 demonstrates that governments are influential throughout the $\mathrm{CH}$ stakeholder ecosystem, as they fund many short-term projects and initiate the infrastructure required for $\mathrm{CH}$ 's implementation.

Academia allows the research, discovery, innovation, and transfer of knowledge regarding $\mathrm{CH}$ processes to entities such as government stakeholders, and academic stakeholders are influential throughout the $\mathrm{CH}$ ecosystem. Although academia is primarily involved in the development of $\mathrm{CH}$ technology, it has become increasingly involved in the social, business, and marketing aspects of value-centric $\mathrm{CH}$.

Finally, industry stakeholders are major players in the $\mathrm{CH}$ ecosystem who offer services and manufacturing products for use by end users. Industry covers a variety of domains: (1) 
software developers, (2) hardware manufacturers, (3) total solution providers, (4) $\mathrm{CH}$ service providers, (5) network services, and (6) end-user stakeholders. Besides the three major stakeholders mentioned above, other actors in the $\mathrm{CH}$ system include patients, patients' families, doctors, nurses, caregivers, and additional persons, primarily volunteers.

Table 4. Themes and word frequencies.

\begin{tabular}{|c|c|}
\hline Theme and words & Word frequency $(\mathrm{N}=61,489), \mathrm{n}(\%)$ \\
\hline \multicolumn{2}{|l|}{ Technology issues } \\
\hline Care & $289(0.47)$ \\
\hline Data & $152(0.25)$ \\
\hline System & $116(0.19)$ \\
\hline Model & $112(0.18)$ \\
\hline Technology & $109(0.18)$ \\
\hline Time & $108(0.18)$ \\
\hline Information & $93(0.15)$ \\
\hline Remote & $79(0.13)$ \\
\hline Distance & $72(0.12)$ \\
\hline Concept & $64(0.10)$ \\
\hline Support & $64(0.10)$ \\
\hline Research & $61(0.10)$ \\
\hline Staff & $61(0.10)$ \\
\hline Personal & $60(0.10)$ \\
\hline Policy & $60(0.10)$ \\
\hline Measuring & $57(0.09)$ \\
\hline Cost & $53(0.09)$ \\
\hline Innovation & $53(0.09)$ \\
\hline Quality & $48(0.08)$ \\
\hline Mobile & $40(0.07)$ \\
\hline Cloud & $42(0.07)$ \\
\hline Device & $39(0.06)$ \\
\hline Smart & $34(0.06)$ \\
\hline \multicolumn{2}{|c|}{ Organization issues } \\
\hline Government & $95(0.15)$ \\
\hline System & $116(0.19)$ \\
\hline Business & $189(0.31)$ \\
\hline Model & $112(0.18)$ \\
\hline Support & $64(0.10)$ \\
\hline Concept & $64(0.10)$ \\
\hline Staff & $61(0.10)$ \\
\hline Public & $68(0.11)$ \\
\hline \multicolumn{2}{|c|}{ Leadership and management issues } \\
\hline Management & $83(0.14)$ \\
\hline Support & $64(0.10)$ \\
\hline Time & $108(0.18)$ \\
\hline Research & $61(0.10)$ \\
\hline Concept & $64(0.10)$ \\
\hline
\end{tabular}


Figure 4. Diagram of connected health players and stakeholder relationships (Chen, 2018 [34]).

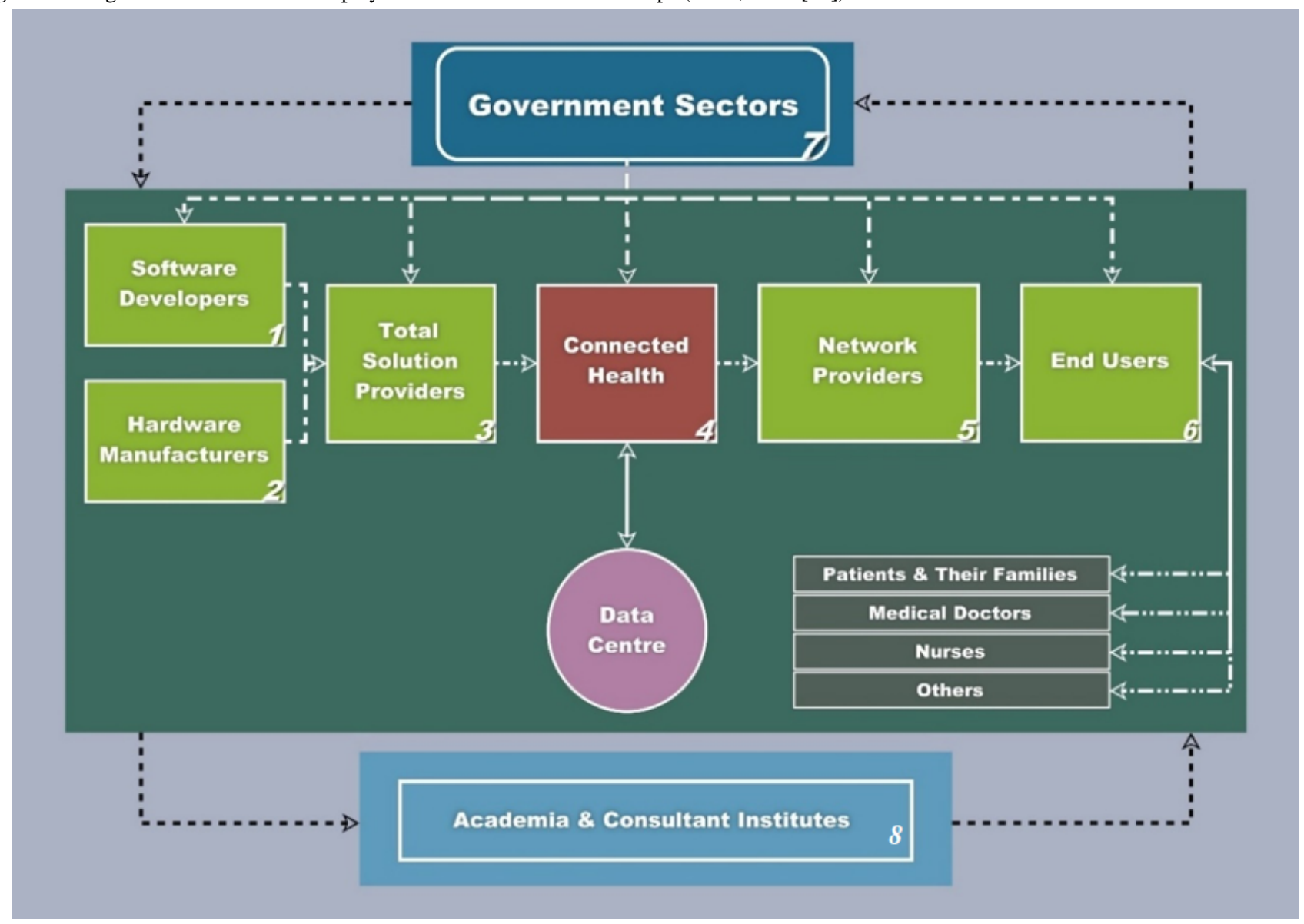

\section{Connected Health as a Coexistent Ecosystem}

Smart health care via a $\mathrm{CH}$ platform explores how health care and technology can coexist, each dependent on the other, rather than operating as separate entities in the $\mathrm{CH}$ ecosystem. This coexistence not only creates a health care system that can better respond to the needs of an aging society, but has the side effect of developing smarter health care methods. Therefore, it is relevant to reconsider the conventional concepts of technology and health care. As an ecosystem, $\mathrm{CH}$ is surrounded by software providers, hardware manufacturers, and health care professionals (see Figure 4).

As far as the sensitive nature of health care data is concerned, cybersecurity plays an important role in ensuring the safety of patients' data. Therefore, it is critical to include the role of information technology (IT) security specialists in the $\mathrm{CH}$ ecosystem. They are incorporated within both the categories software developers and hardware manufacturers. Other relevant roles are covered in these eight categories, even though not all of them are named in Figure 4. For example, the role stakeholders with standardization is included within the category academia and consultant institutes. What is noticeable is that the role of interoperability personnel still remains to be developed according to many cases interviewed, although this role is essential for the success of CH's implementation.

Followed by the main stakeholders in Figure 4, the classification of organizations and participants interviewed is provided in Table 5. This table classified the 60 participants from 34 organizations into eight categories according to the categories in Figure 4. When we found that some organizations bridged two or three categories, we classified them according to their main businesses. Despite having their own businesses and business concerns, they have to coexist to activate CH's implementation.

\section{Connected Health as a Platform of Remote Monitoring and Self-Management}

This section presents the interview results regarding how $\mathrm{CH}$ functions as a platform of remote monitoring and self-management, based on the perspectives of participants shown in Table 6. 
Table 5. The classification of organizations interviewed.

\begin{tabular}{ll}
\hline Category and numbers & Organization name \\
\hline
\end{tabular}

1. Software developers

101

102

\section{Hardware manufacturers}

201

202

203

204

205

3. Total solution providers

301

302

303

304

305

4. Connected health $(\mathrm{CH})$ service providers

401

402

403

404

405

406

407

5. Network providers

\section{End users}

601

602

603

604

605

7. Government sectors

701

702

703

704

\section{Academia}

801

802

803

804

805
Far EasTone Telecommunications Smart City Division

Guidercare

Netown Corporation

Far EasTone Telecommunications Technical Department Huede Technology

Guidercare

Acomotech

Netown Corporation

Far EasTone Telecommunications

Huede

Guidercare

Acomotech

Luo Dong Care Institute

En Chu Kong Hospital

Taoyuan Fu Hsing Township Health Station

Taipei Medical University, Telehealth \& Telecare Center

Mennonite Christian Hospital

Taiwan University Hospital, Telehealth Center

Taiwan University Hospital

Far EasTone Telecommunications

National Taiwan University Hospital

Mennonite Christian Hospital

Taipei Medical University, Telehealth \& Telecare Center

En Chu Kong Hospital

Luo Dong Care Institute

Health \& Welfare Department

Sang Chung Health Center

Luo Dong Care Institute

Taoyuan Fu Hsing Township Health Station

National Taiwan University, Engineering Department

National Taipei University of Technology

Taipei University

UL (Underwriters Laboratories) Life \& Health

National Taiwan University, Medicine Department 
Table 6. Participants' perspectives regarding how connected health $(\mathrm{CH})$ functions as a platform of remote monitoring and self-management.

\begin{tabular}{|c|c|c|}
\hline Participants & Summary & Quotes \\
\hline 1 and 7 & $\begin{array}{l}\text { Most interviewees indicated that remote service is a promising } \\
\text { solution for working adults who have to balance multiple priorities } \\
\text { in limited time and care for aging parents or dependents. In a } \mathrm{CH} \\
\text { ecosystem, their parents might receive services remotely, with } \\
\text { smart and precise features tailored to their specific course of } \\
\text { treatment. Some respondents indicated that they were willing to } \\
\text { receive smart services if these services were available and accessi- }\end{array}$ & $\begin{array}{l}\text { - "It will be beneficial if remote services are available to } \\
\text { look after both parents and children at home. At the same } \\
\text { time, sending older parents to a care institution is not our } \\
\text { culture after all." [Participant \#1] } \\
\text { "Remote solutions offer residents in rural areas efficient } \\
\text { and cost-effective options to receive health care services." } \\
\text { [Participant \#7] }\end{array}$ \\
\hline
\end{tabular}
ble in their areas. Additionally, smart, precise, alternative health care solutions effectively reduced the restraints placed on care through the time and cost of travelling, particularly for patients who were located outside of major metropolitan areas.

37, 4, 15, and 20 Many interviewees agreed that, apart from alternative solutions, remote services add value to health care centers by ensuring that stakeholders and players in the $\mathrm{CH}$ ecosystem remain informed and connected. These services not only enable residents in lesspopulated areas to receive health care services, they ameliorate patients' concerns about being isolated from essential health care services and needs.

- $\quad$ "Our customers are connected with hospital care, thanks to the remote monitoring." [Participant \#37]

- $\quad$ "Remote services make the scalability of health care possible." [Participant \#4]

- $\quad$ "A professional exchange of opinions is enabled through remote service." [Participant \#15]

- "Our remote device and service enable patients to be monitored at home after their surgery...Both patients and the hospital can benefit from this facility." [Participant \#20]

43, 4, and $37 \quad$ Although some industrial stakeholders believed that health care should be localized, some policy makers believed that Taiwan could attract international visitors by promoting medical tourism, which would allow a future scaling-up of health care businesses as these individuals pay for and receive comprehensive services. Whether the Taiwanese health care model and service can be expanded overseas is still debatable; however, what is certain is that the results suggest that remote services are particularly helpful for overseas businesspeople since these services offer seamless, timely, health-monitoring services. Participants made comments regarding medical tourism in the Taiwanese context (see quotes in next column).

10,14 , and 13 Whether a one-size-fits-all approach to remote services is feasible is debatable. Some conventional health care providers are conservative in their implementation of remote practices. Concerns expressed included the costs of initiating investment in infrastructure and ensuring a return on those investments. Health professionals continued to disagree as to whether remote services can actually translate to more effective care or can replace personal providerpatient interactions. Although these are future trends in health care, some doctors still held more conservative views.

The stakeholders that we interviewed suggested that scarce $\mathrm{CH}$ resources and funding should be directed to effective health care services in more remote areas, because many urban areas already offer effective health care services (see quote in the next column). Additionally, government support and incentives, such as awarding funding based on $\mathrm{CH}$ performance measures, may be crucial to motivate or reward health care professionals and stakeholders.

Our interviewees expressed the importance of increasingly rapid innovation within the $\mathrm{CH}$ business model so that services can maximize the utility of current developments in $\mathrm{CH}$-related technology, including remote sensing and rapid central analysis capabilities. The doctors expressing this view were primarily general practitioners with a business model and related funding, and their work mostly centered on patients who visited the general practitioners at a specific location for care (see quote in next column by a doctor working in a rural area).

- $\quad$ "I think medical services should remain localized as they are developed according to local needs and culture." [Participant \#43]

- $\quad$ "Taiwan has excellent health and medical products and services; these advantages should be attractive to international tourists...It is a good opportunity for us to develop medical tourism.” [Participant \#4]

- "Many of our customers are Taiwanese businessmen who work in mainland China...we have expanded the telehealth service from the island of Taiwan to include mainland China..." [Participant \#37]

- "Remote service is an ideal option; however, due to our business scale and direction, we are not yet offering this service." [Participant \#10]

- $\quad$ "In the short term, remote service can be a sponsored pilot program; however, a significant amount of time is needed to receive its return on investment." [Participant \#14]

- "After a decade of practicing medical service, I personally believe health care should be implemented face-to face...” [Participant \#13]

- $\quad \mathrm{CH}$ is essential in remote areas. It provides residents with access to health care services."

- "Although we seem to lack resources compared to urban areas, as long as we can offer unique value propositions, we can obtain essential resources from companies with CH." 


\begin{tabular}{lll}
\hline Participants & Summary & Quotes \\
\hline 13 & $\begin{array}{l}\text { In some of these cases, stakeholders had cultural difficulties with } \\
\text { CH—they argued that human contact between doctor and patient } \\
\text { is irreplaceable and essential to health care. However, many of } \\
\text { them did concede that contact may be flexible. These stakeholders } \\
\text { assumed that CH is a business fad, rather than a necessary practice } \\
\text { for patients. However, these views did not reflect the difficulties } \\
\text { experienced in providing efficient and effective health care in re- } \\
\text { mote regions. }\end{array}$ & $\begin{array}{l}\text { "I have been doing medical services for a decade, and I } \\
\text { support personal contact in health care; for me, connected } \\
\text { health is just one of the formats of a business fad..." }\end{array}$ \\
&
\end{tabular}

Several industry interviewees seemed more concerned about the development of technology and its potential applications for $\mathrm{CH}$ than end users, based on their perceptions and their need for therapeutic care. This suggests more effective stakeholder interaction and business model innovation are required to coordinate end users' needs and industrial provisions. Additionally, all industry interviewees were concerned about the sustainability of $\mathrm{CH}$ businesses beyond grant funding, and therefore emphasized the need to align technology development with a sustainable business model. These interviewees tended to use their connections and relationships to promote nascent supply chains for $\mathrm{CH}$ businesses that required more systematic development. In contrast, many academic interviewees considered $\mathrm{CH}$ as an emergent topic of innovation and cited a need for more interdisciplinary research and education beyond technological developments.

\section{Discussion}

\section{Principal Findings}

$\mathrm{CH}$ as a coexistent ecosystem includes all the stakeholders who work together to facilitate its implementation. Patients' security and privacy are crucial concerns in the implementation process [36]. However, our interviewees indicated that their main priority is to test the feasibility of remote health care services, as all such services are required to follow current regulations concerning patients' safety. This does not suggest that security and privacy issues can be compromised in exchange for ease of accessibility for health professionals and industry players [37]. On the contrary, following such standards is the precondition of practicing $\mathrm{CH}$, even if some stakeholders think that there is no need to overemphasize the importance of following these standards. Below, we consider a few important issues and obstacles to implementing $\mathrm{CH}$.

\section{Security Concerns}

When asked about patients' security concerns, some health professionals emphasized CH's potential convenience and high quality of care. They often asserted that they believe that $\mathrm{CH}$ might be like online banking: offering services anytime, anywhere. In this study, governments bear the most responsibility for controlling the risks of using $\mathrm{CH}$ and for setting standards that will protect patients [38]. Although successful implementation of $\mathrm{CH}$ requires the cooperation of all stakeholders, only those who have power and impacts in the ecosystem can make final decisions regarding CH's implementation. This explains why IT security professionals may not have the power to make decisions in the ecosystem, even though they play important roles.
Opinions regarding privacy and security differ. Some health professionals believe that patients' and institutions' security should be prioritized above the convenience of $\mathrm{CH}$ services, but others believe that efforts to make $\mathrm{CH}$ more feasible and effective should come first. In general, it is difficult to get all stakeholders to share common ground [39]. The power of decision making usually distinguishes the leaders in the ecosystem. This can be seen from the conversation between the government sectors and industry players. The latter expect government to form the standard of protocol, while the former insist on the respect of the free market.

\section{Interdisciplinary Talent}

According to our interviewees, health professionals and governments have more power in the process of implementing $\mathrm{CH}$ than industry or patients. Industry usually follows government policies, as their products and services often require governments to initiate funding and infrastructure for the realization of these projects [40]. Patients' needs are often interpreted through health professionals. Respondents indicated that interdisciplinary staff is crucial to enable the smooth operation of $\mathrm{CH}$; however, it takes time to train and develop talents.

\section{Connected Health as a Platform to Facilitate Smart Health Care}

Although many efforts have been made to improve the quality of health care, treating some diseases remains challenging because many caregivers and patients lack the information they need for effective treatment. Although $\mathrm{CH}$ provides a wide range of care delivery models, it can also be used simply to connect patients with the information they need for effective treatment [41]. In this way, $\mathrm{CH}$ provides a pathway to smart, precise health care. $\mathrm{CH}$ can put power back into the hands of patients [42], and the data collected from $\mathrm{CH}$ platforms can enable the provision of smart health care [43]. Through big data and artificial intelligence technologies, $\mathrm{CH}$ offers a platform that enables smart homes, smart cities, and patient-centered, personalized health interventions $[44,45]$.

\section{Connected Health's Innovative Strategies Based on Value Propositions}

Scholars at Harvard Business School have discussed three innovation strategies that reflect how timely, smart, and targeted health care can be met through a $\mathrm{CH}$ platform. These strategies are the infuse and augment strategy, the combine and transcend strategy, and the counteract and reaffirm strategy [19].

The infuse and augment strategy involves the development of new services and products under the current service structure, without significant change to the attributes and functions of that 
structure. This strategy increases and emphasizes elements that deliver services that meet the needs and desires that are presently unfulfilled by major markets. A case in point is the Changhua Christian Hospital's (CCH) eHealth and Diabetes Health Management Center, which was created in 2013 to meet the needs of an aging population with an increasing level of chronic health conditions. $\mathrm{CCH}$ had been a symbol of public welfare and social care for over a century, and many observers thought that the most plausible reaction to an aging society would have been to reduce the cost of care. However, the $\mathrm{CCH}$ believed that reducing the cost of care would have jeopardized the quality of care. Instead, $\mathrm{CCH}$ engaged with global institutions from developed countries, from which the trend of aging in place emerged:

For over a century, $\mathrm{CCH}$ has been playing the role of health care hub in the mid-south of Taiwan; now we are expanding our services and business to the global context. [Participant \#55]

Furthering this argument from the patient perspective, individuals prefer to remain in a familiar location, and may prefer to manage their own health rather than increase the number of medications they take. These insights explain why the $\mathrm{CCH}$ opted to create the aforementioned center instead of reducing the cost of care. Such a center offers more comprehensive and cost-effective services than conventional care. Creating the center allowed the $\mathrm{CCH}$ to avoid an across-the-board price reduction, in contrast to many hospitals that have responded to aging populations by reducing costs. In this case, the $\mathrm{CCH}$ viewed global market trends as opportunities for innovation and renewal:

We are proactive in absorbing new practices and exploring global trends...We discovered that our customers tend to follow the concept of "aging in place," which echoes the global trend. [Participant \#55]

The head of the hospital is really supportive regarding both finances and resources in initiating this center so that we can offer a comprehensive service to our customers. [Participant \#55]

Taipei Medical University Hospital's (TMUH) answer to an aging population's call for seamless services represents another example of the infuse and augment strategy. One of the top hospitals in Taipei, TMUH introduced its telehealth-care service program in 2007, which offers consultation and over-the-phone care for patients outside standard working hours. This was achieved by integrating resources and increasing connected services. For example, customers who join the telehealth-care program are able to consult doctors online and book an appointment in advance. Connected devices, meal delivery, and laundry services are also available to ensure seamless and complete care. By augmenting its traditional health care services with these innovations, TMUH has thereby infused its value proposition with an online service:

Our clients can obtain access to health care information anytime they need to, even during out-of-office time. [Participant \#34]
We hope that our customers can use health care services in the future as if they are using online banking: 24 hours, seamless services. [Participant \#34]

The combine and transcend strategy offers a different, relatively radical approach to implementing $\mathrm{CH}$. This strategy involves combining features of a service's existing value propositions with quality-transferring changes arising from a trend. In this way, a novel experience is created, one which may lead the institution into a new market space. At first glance, employing resources to incorporate elements of a different domain into one's core offerings sounds like it is not worthwhile. However, TaiDoc's shift to integrate medical sensing solutions into its reputation for its integrated circuit design demonstrates how the combine and transcend strategy can be successful. In 2002, TaiDoc joined with hospitals to develop biosensing devices that can monitor patients' health conditions remotely. By combining TaiDoc's original value propositions for electronic supplies with those of health providers, the company entered a new field of engagement with the health sector. Within a decade, TaiDoc became the top manufacturer of blood glucose medical devices and now accounts for a significant share of the global market.

When the sales manager was asked why they are determined to jump into the business of medical devices, the response was as follows:

We are determined to expand our business to medical devices as our founder encountered an emerging need from his family. [Participant \#31]

As long as we saw the needs corresponding to the trend, we took the leap...although it was challenging, we enjoyed the fruits of success within 10 years. [Participant \#45]

Another example of the combine and transcend strategy is the case of Far EasTone Telecommunications. After seeing the potential of a smart health care industry, Far EasTone Telecommunications combined telecommunication services with medical devices to enable telehealth-care services. In order to make this transcendence of existing capabilities possible, they encouraged engineers to engage in work-related training and introduced their test models in their partnered hospitals. Far EasTone Telecommunications has now expanded their businesses to over 80 hospitals and institutions within the past 5 years and has become a leading telehealth services provider in Taiwan.
Our manager has an insightful vision of the market; she believes that telehealth-care will become a leading industry in the future. [Participant \#18]
Our boss considers a telehealth-care service to be a long-term strategy. He allows exploring of possibilities for a period of time and believes that success will come soon. [Participant \#18]

The counteract and reaffirm strategy entails understanding disagreements with the value statements of current services or products and reclaiming a new value proposition that is considered to be superior to existing values. An example of such a service is the Nanwui Foundation, a health and social 
care service established by a local physician from Tai-tong Health Center. Like other health facilities, they offer general health care services and health checks. However, the Nanwui Foundation also incorporates the fundamental needs of remote areas into its service manifesto; it holds educational workshops and has a green farm community, which allows residents to explore their values and elaborate on their talents. The case of the Nanwui Foundation supports the assertion that health care is not only about people's physical health care needs, but also their need for dignity. Our interviewees reflected that patients are happier and healthier when they have a goal to pursue and a stage to play on:

When I saw these patients, they appeared old, poor, and weak, but when they participated in the social workshops that I organized, they became energetic and healthy. [Participant \#57]

Physical conditions are only a partial reflection of their health conditions...offering them a stage on which to perform that allows them to exert that their value may be more relevant to their well-being. [Participant \#57]

In remote areas, residents are poor and lack medical resources. When there is no Superman, we can be our own Superman. [Participant \#57]

\section{Connected Health's Innovative Strategies}

Although $\mathrm{CH}$ seems to provide promising solutions for the problems posed by an aging population with many chronic health conditions, these solutions are not easy or quick-innovative implementation strategies are required to enable its practices [46]. This is especially true because the players in the $\mathrm{CH}$ ecosystem compete for the same organizational resources and stakeholders. Therefore, each actor in the ecosystem needs to adopt different strategies to help them differentiate their value propositions and obtain useful resources [47]. Some interviewees indicated that many $\mathrm{CH}$ players failed due to lack of strategic planning. Therefore, this study adapted the strategies proposed by scholars to demonstrate how organizations use strategies to succeed with $\mathrm{CH}$. These experiences may inspire players in various industries.

\section{Limitations and Future Work}

This study explored how timely, smart, and targeted health care can be achieved through $\mathrm{CH}$ platforms. This means that some relevant content, such as a detailed stakeholder analysis, comprehensive consideration of security and privacy concerns, and detailed assessments of business models, was not described in a large amount of detail. These topics can be extended in future work to offer an inclusive picture of $\mathrm{CH}$ implementation. Apart from that, this study is based on the Taiwanese context and different cultural perspectives can be introduced and included in future studies.

\section{Conclusions}

This study makes a relevant contribution to the literature by exploring perspectives on how trend-associated changes in customers' opinions and behaviors influences health care and social care. Once these trends have been identified on a broad scale, appropriate innovation and intervention strategies can be developed and implemented. When innovation and entrepreneurship are correctly combined, $\mathrm{CH}$ businesses can be propelled and spectacular results can be expected. The infuse and augment strategy will permit $\mathrm{CH}$ businesses to emerge in successful and socially beneficial ways if the essential values of these businesses remain meaningful to consumers who engage with the service trends. If the results imply that the value statements are incongruent with consumers' new expectations, it suggests that the current innovation strategy is insufficient and needs to be transcended or combined with another strategy to create a new value statement. If the current solutions are associated with negative impacts or conflict with the mainstream system, counteracting these aspects by reaffirming the core values of your business is an ideal strategy. The findings indicate that strategic planning could be beneficial to leverage resources for the implementation of $\mathrm{CH}$. Moreover, continually revisiting business models and strategies is essential because of the rapid, ongoing technological changes across $\mathrm{CH}$ stakeholder groupings. In short, we believe that timely, smart, and targeted health care can be created through a $\mathrm{CH}$ platform.

\section{Acknowledgments}

This research was partially supported by the Vice Chancellor Research Studentship from Ulster University, and SC Limited Company. The APC was funded by Huaqiao University High-level Talent Research Project and The Straits Postdoctoral Fellowship Funding Program in 2018, Fujing Financial office no [2017] 32/605 50X18137. All authors made equal contributions. The authors would like to thank the supervisors, Professor Rodney McAdam, Dr Michael Brennan, and Dr Shirley Davey from Ulster University, for sharing their pearls of wisdom during this research. The authors are also immensely grateful to Mr Ray Palmer and David Liu for their comments on an earlier version of the manuscript.

\section{Conflicts of Interest}

None declared.

\section{Multimedia Appendix 1}

Word frequency cloud of the interview data.

[PNG File, 585 KB-Multimedia Appendix 1]

\section{References}


1. Barr PJ, McElnay JC, Hughes CM. Connected health care: The future of health care and the role of the pharmacist. J Eval Clin Pract 2012 Feb;18(1):56-62. [doi: 10.1111/j.1365-2753.2010.01522.x] [Medline: 20698917]

2. Eysenbach G. What is e-health? J Med Internet Res 2001;3(2):E20 [FREE Full text] [doi: 10.2196/jmir.3.2.e20] [Medline: 11720962]

3. Della Mea V. What is e-health (2): The death of telemedicine? J Med Internet Res 2001;3(2):E22 [FREE Full text] [doi: 10.2196/jmir.3.2.e22] [Medline: 11720964]

4. Chouvarda IG, Goulis DG, Lambrinoudaki I, Maglaveras N. Connected health and integrated care: Toward new models for chronic disease management. Maturitas 2015 Sep;82(1):22-27. [doi: 10.1016/j.maturitas.2015.03.015] [Medline: 25891502]

5. Carroll N. Key success factors for smart and connected health software solutions. Computer 2016 Nov;49(11):22-28. [doi: 10.1109/MC.2016.340]

6. O'Leary P, Carroll N, Clarke P, Richardson I. Untangling the complexity of connected health evaluations. In: Proceedings of the 2015 International Conference on Healthcare Informatics. New York, NY: IEEE; 2015 Oct 21 Presented at: 2015 International Conference on Healthcare Informatics; October 21-23, 2015; Dallas, TX p. 272-281 URL: https://ieeexplore. ieee.org/abstract/document/7349700 [doi: $10.1109 /$ ichi.2015.39]

7. Kellermann AL, Jones SS. What it will take to achieve the as-yet-unfulfilled promises of health information technology. Health Aff (Millwood) 2013 Jan;32(1):63-68. [doi: 10.1377/hlthaff.2012.0693] [Medline: 23297272]

8. Darkins A, Ryan P, Kobb R, Foster L, Edmonson E, Wakefield B, et al. Care coordination/home telehealth: The systematic implementation of health informatics, home telehealth, and disease management to support the care of veteran patients with chronic conditions. Telemed J E Health 2008 Dec;14(10):1118-1126. [doi: 10.1089/tmj.2008.0021] [Medline: 19119835]

9. Rheuban K, Shanahan C, Willson K. Telemedicine: Innovation has outpaced policy. Virtual Mentor 2014 Dec 01;16(12):1002-1009 [FREE Full text] [doi: 10.1001/virtualmentor.2014.16.12.pfor1-1412] [Medline: 25493370]

10. Xu L, Wu F. Cryptanalysis and improvement of a user authentication scheme preserving uniqueness and anonymity for connected health care. J Med Syst 2015 Feb;39(2):10. [doi: 10.1007/s10916-014-0179-x] [Medline: 25631840]

11. Galbraith B, Mulvenna M, McAdam R, Martin S. Open innovation in connected health: An empirical study and research agenda. In: Proceedings of the XIX International Society for Professional Innovation Management (ISPIM) Conference. Manchester, UK: International Society for Professional Innovation Management; 2008 Jun 15 Presented at: XIX International Society for Professional Innovation Management (ISPIM) Conference; June 15-18, 2008; Tours, France URL: https://www. researchgate.net/profile/Maurice Mulvenna/publication/

228373568 Open innovation in Connected Health an empirical study and research agenda/links/ 542307530cf26120b7a6b92d/Open-innovation-in-Connected-Health-an-empirical-study-and-research-agenda.pdf

12. Das AK, Goswami A. A secure and efficient uniqueness-and-anonymity-preserving remote user authentication scheme for connected health care. J Med Syst 2013 Jun;37(3):9948. [doi: 10.1007/s10916-013-9948-1] [Medline: 23660745]

13. Fernandez-Luque L, Vilmarlund V, Borycki E, Schulz S, Kuziemsky C, Marschollek M, et al. Social media as catalyzer for connected health: Hype or hope? Perspectives from IMIA working groups. Stud Health Technol Inform 2016;225:602-604. [Medline: 27332272]

14. Caulfield BM, Donnelly SC. What is connected health and why will it change your practice? QJM 2013 Aug;106(8):703-707. [doi: 10.1093/qjmed/hct114] [Medline: 23676416]

15. Burke LE, Ma J, Azar KM, Bennett GG, Peterson ED, Zheng Y, et al. Current science on consumer use of mobile health for cardiovascular disease prevention. Circulation 2015 Sep 22;132(12):1157-1213. [doi: 10.1161/CIR.0000000000000232]

16. Brandenburger A, Stuart J. Value - based business strategy. J Econ Manag Strategy 1996;5(1):5-24 [FREE Full text] [doi: 10.1111/j.1430-9134.1996.00005.x]

17. Yu C. Building a value-centric e-government service framework based on a business model perspective. Int Conf Electron Gov 2008;5184:160-171. [doi: 10.1007/978-3-540-85204-9 14]

18. Ehrenhöfer C, Kreuzer E. The role of business model design in the service engineering process: A comparative case study in the field of cloud computing to join service engineering with business model design. In: Proceedings of the 2012 Annual Service Research and Innovation Institute (SRII) Global Conference. New York, NY: IEEE; 2012 Jul 24 Presented at: 2012 Annual Service Research and Innovation Institute (SRII) Global Conference; July 24-27, 2012; San Jose, CA p. $283-292$. [doi: $10.1109 /$ srii.2012.39]

19. Ofek E, Wathieu L. Are you ignoring trends that could shake up your business? In: Harvard Business Review on Rebuilding Your Business Model. Boston, MA: Harvard Business School Publishing Corporation; 2011:87-106.

20. Breuer H, Lüdeke-Freund F. Values-Based Innovation Management: Innovating by What We Care About. London, UK: Palgrave; 2017.

21. Weinstein RS, Lopez AM. Health literacy and connected health. Health Aff (Millwood) 2014 Jun;33(6):1103-1104. [doi: 10.1377/hlthaff.2014.0396] [Medline: 24889963]

22. Chesbrough H. Business model innovation: It's not just about technology anymore. Strategy Leadersh 2007 Nov 13;35(6):12-17. [doi: 10.1108/10878570710833714]

23. Barclay L. In sickness and in dignity: A philosophical account of the meaning of dignity in health care. Int J Nurs Stud 2016 Sep;61:136-141. [doi: 10.1016/j.ijnurstu.2016.06.010] [Medline: 27351830] 
24. Agboola SO, Ball M, Kvedar JC, Jethwani K. The future of connected health in preventive medicine. QJM 2013 Sep;106(9):791-794. [doi: 10.1093/qjmed/hct088] [Medline: 23598385]

25. Iglehart JK. Connected health: Emerging disruptive technologies. Health Aff (Millwood) 2014 Feb;33(2):190. [doi: 10.1377/hlthaff.2014.0042] [Medline: 24493758]

26. Friedman CP, Rubin JC, Sullivan KJ. Toward an information infrastructure for global health improvement. Yearb Med Inform 2017 Aug;26(1):16-23 [FREE Full text] [doi: 10.15265/IY-2017-004] [Medline: 28480469]

27. Rogers WA, Mitzner TL. Envisioning the future for older adults: Autonomy, health, well-being, and social connectedness with technology support. Futures 2017 Mar;87:133-139 [FREE Full text] [doi: 10.1016/i.futures.2016.07.002] [Medline: 28458395]

28. Zahran Z, Tauber M, Watson HH, Coghlan P, White S, Procter S, et al. Systematic review: What interventions improve dignity for older patients in hospital? J Clin Nurs 2016 Feb;25(3-4):311-321. [doi: 10.1111/jocn.13052] [Medline: 26818360]

29. Yin RK. Applications of Case Study Research. 3rd edition. Thousand Oaks, CA: SAGE Publications; 2012.

30. Shaw T, McGregor D, Brunner M, Keep M, Janssen A, Barnet S. What is eHealth (6)? Development of a conceptual model for eHealth: Qualitative study with key informants. J Med Internet Res 2017 Oct 24;19(10):e324 [REE Full text] [doi: 10.2196/jmir.8106] [Medline: 29066429]

31. Carson D, Gilmore A, Perry C, Gronhaug K. Qualitative Marketing Research. London, UK: SAGE Publications; 2001.

32. Pattison PE, Robins GL, Snijders TA, Wang P. Conditional estimation of exponential random graph models from snowball sampling designs. J Math Psychol 2013 Dec;57(6):284-296. [doi: 10.1016/j.jmp.2013.05.004]

33. Rourke L, Anderson T. Validity in quantitative content analysis. Educ Technol Res Dev 2004 Mar;52(1):5-18. [doi: 10.1007/BF02504769]

34. Chen SC. Technological health intervention in population aging to assist people to work smarter not harder: Qualitative study. J Med Internet Res 2018 Jan 04;20(1):e3 [FREE Full text] [doi: 10.2196/jmir.8977] [Medline: 29301736]

35. Carroll N, Travers M, Richardson I. Evaluating multiple perspectives of a connected health ecosystem. In: Proceedings of the 9th International Conference on Health Informatics (HEALTHINF). 2016 Feb 21 Presented at: 9th International Conference on Health Informatics (HEALTHINF); February 21-23, 2016; Rome, Italy URL: http://hdl.handle.net/10344/ $\underline{5442}$ [doi: $10.5220 / 0005623300170027$ ]

36. Hale T, Kvedar J. Privacy and security concerns in telehealth. Virtual Mentor 2014 Dec 01;16(12):981-985 [FREE Full text] [doi: 10.1001/virtualmentor.2014.16.12.jdsc1-1412] [Medline: 25493367]

37. Hall JL, McGraw D. For telehealth to succeed, privacy and security risks must be identified and addressed. Health Aff (Millwood) 2014 Feb;33(2):216-221. [doi: 10.1377/hlthaff.2013.0997] [Medline: 24493763]

38. Mandel JC, Kreda DA, Mandl KD, Kohane IS, Ramoni RB. SMART on FHIR: A standards-based, interoperable apps platform for electronic health records. J Am Med Inform Assoc 2016 Sep;23(5):899-908 [FREE Full text] [doi: 10.1093/jamia/ocv189] [Medline: 26911829]

39. Hoffman A, Montgomery R, Aubry W, Tunis SR. How best to engage patients, doctors, and other stakeholders in designing comparative effectiveness studies. Health Aff (Millwood) 2010 Oct;29(10):1834-1841. [doi: 10.1377/hlthaff.2010.0675] [Medline: 20921483]

40. Steele R, Min K, Lo A. Personal health record architectures: Technology infrastructure implications and dependencies. Acta Anaesthesiol Scand 2012 Mar 05;63(6):1079-1091. [doi: 10.1002/asi.22635]

41. Jethwani K, Ling E, Mohammed M, Myint-U K, Pelletier A, Kvedar JC. Diabetes connect: An evaluation of patient adoption and engagement in a Web-based remote glucose monitoring program. J Diabetes Sci Technol 2012 Nov 01;6(6):1328-1336 [FREE Full text] [doi: 10.1177/193229681200600611] [Medline: 23294777]

42. Chu LF, Shah AG, Rouholiman D, Riggare S, Gamble JG. Patient-centric strategies in digital health. In: Rivas H, Wac K, editors. Digital Health: Scaling Healthcare to the World. Cham, Switzerland: Springer; 2018:43-54.

43. Pramanik MI, Lau RY, Demirkan H, Azad MA. Smart health: Big data-enabled health paradigm within smart cities. Expert Syst Appl 2017 Nov;87:370-383. [doi: 10.1016/j.eswa.2017.06.027]

44. Muhammad G, Rahman SM, Alelaiwi A, Alamri A. Smart health solution integrating IoT and cloud: A case study of voice pathology monitoring. IEEE Commun Mag 2017 Jan;55(1):69-73. [doi: 10.1109/mcom.2017.1600425cm]

45. Kvedar J, Coye MJ, Everett W. Connected health: A review of technologies and strategies to improve patient care with telemedicine and telehealth. Health Aff (Millwood) 2014 Feb;33(2):194-199. [doi: 10.1377/hlthaff.2013.0992] [Medline: $\underline{24493760}$

46. Slama D, Puhlmann F, Morrish J, Bhatnagar R. Enterprise IoT: Strategies and Best Practices for Connected Products and Services. Sebastopol, CA: O'Reilly Media; 2015.

47. Vest JR, Kash BA. Differing strategies to meet information-sharing needs: Publicly supported community health information exchanges versus health systems' enterprise health information exchanges. Milbank Q 2016 Mar;94(1):77-108 [FREE Full text] [doi: 10.1111/1468-0009.12180] [Medline: 26994710]

\section{Abbreviations}

AMA: American Medical Association 
BMI: Business Model Innovation

CCH: Changhua Christian Hospital

CH: connected health

ICT: information and communication technology

IT: information technology

TMUH: Taipei Medical University Hospital

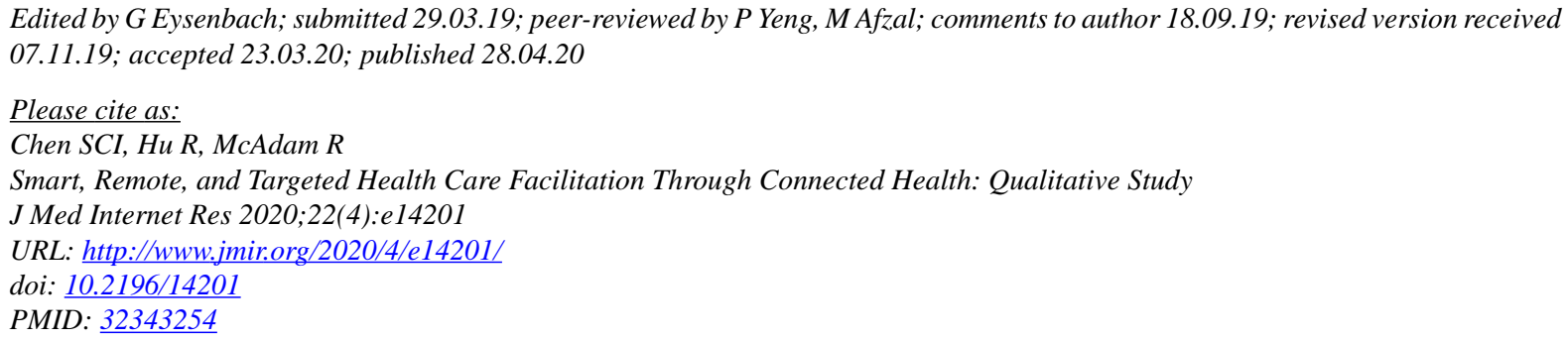

(C) Sonia Chien-I Chen, Ridong Hu, Rodney McAdam. Originally published in the Journal of Medical Internet Research (http://www.jmir.org), 28.04.2020. This is an open-access article distributed under the terms of the Creative Commons Attribution License (https://creativecommons.org/licenses/by/4.0/), which permits unrestricted use, distribution, and reproduction in any medium, provided the original work, first published in the Journal of Medical Internet Research, is properly cited. The complete bibliographic information, a link to the original publication on http://www.jmir.org/, as well as this copyright and license information must be included. 